Chapman University

Chapman University Digital Commons

2013

\title{
How Universal is the Big Five? Testing the Five-Factor Model of Personality Variation Among Forager-Farmers in the Bolivian Amazon
}

\author{
Michael Gurven \\ University of California, Santa Barbara \\ Christopher von Rueden \\ University of California, Santa Barbara \\ Maxim Massenkoff \\ University of California, Santa Barbara \\ Hillard Kaplan \\ Chapman University, hkaplan@chapman.edu \\ Marino Lero Vie \\ Tsimane Health and Life History Project, Bolivia \\ Follow this and additional works at: https://digitalcommons.chapman.edu/esi_pubs \\ Part of the Biological and Physical Anthropology Commons, Economic Theory Commons, Ethnic \\ Studies Commons, Latin American Studies Commons, Other Anthropology Commons, Other Economics \\ Commons, and the Social and Cultural Anthropology Commons
}

\section{Recommended Citation}

Gurven, M., von Rueden, C., Massenkoff, M., Kaplan, H., \& Lero Vie, M. (2013). How universal is the Big Five? Testing the five-factor model of personality variation among forager-farmers in the Bolivian Amazon. Journal of Personality and Social Psychology, 104(2), 354-370. https://doi.org/10.1037/ a0030841 


\title{
How Universal Is the Big Five? Testing the Five-Factor Model of Personality Variation Among Forager-Farmers in the Bolivian Amazon
}

\author{
Michael Gurven, \\ Department of Anthropology, University of California, Santa Barbara \\ Christopher von Rueden, \\ Department of Anthropology, University of California, Santa Barbara \\ Maxim Massenkoff, \\ Department of Anthropology, University of California, Santa Barbara \\ Hillard Kaplan, and \\ Department of Anthropology, University of New Mexico \\ Marino Lero Vie \\ Tsimane Health and Life History Project, San Borja, Beni, Bolivia
}

\section{Abstract}

\begin{abstract}
The five-factor model (FFM) of personality variation has been replicated across a range of human societies, suggesting the FFM is a human universal. However, most studies of the FFM have been restricted to literate, urban populations, which are uncharacteristic of the majority of human evolutionary history. We present the first test of the FFM in a largely illiterate, indigenous society. Tsimane forager-horticulturalist men and women of Bolivia $(n=632)$ completed a translation of the 44-item Big Five Inventory (Benet-Martínez \& John, 1998), a widely used metric of the FFM. We failed to find robust support for the FFM, based on tests of (a) internal consistency of items expected to segregate into the Big Five factors, (b) response stability of the Big Five, (c) external validity of the Big Five with respect to observed behavior, (d) factor structure according to exploratory and confirmatory factor analysis, and (e) similarity with a U.S. target structure based on Procrustes rotation analysis. Replication of the FFM was not improved in a separate sample of Tsimane adults $(n=430)$, who evaluated their spouses on the Big Five Inventory. Removal of reverse-scored items that may have elicited response biases produced factors suggestive of Extraversion, Agreeableness, and Conscientiousness, but fit to the FFM remained poor. Response styles may covary with exposure to education, but we found no better fit to the FFM among Tsimane who speak Spanish or have attended school. We argue that Tsimane personality variation displays 2 principal factors that may reflect socioecological characteristics common to small-scale
\end{abstract}

(C) 2012 American Psychological Association

Correspondence concerning this article should be addressed to Michael Gurven, Department of Anthropology, University of California, Santa Barbara, CA 93106. gurven@ anth.ucsb.edu.

Supplemental materials: http://dx.doi.org/10.1037/a0030841.supp 
societies. We offer evolutionary perspectives on why the structure of personality variation may not be invariant across human societies.

\section{Keywords}

personality; Big Five; five-factor model (FFM); indigenous; Tsimane

The five-factor model (FFM) is a widely accepted construct describing personality variation along five dimensions (i.e., the Big Five): Extraversion, Openness, Conscientiousness, Neuroticism, and Agreeableness. Many researchers have argued that the structure of the FFM is a "biologically based human universal" that transcends language and other cultural differences (Bouchard \& Loehlin, 2001; McCrae \& Costa, 1997; Wiggins \& Trapnell, 1997; Yamagata et al., 2006). Cross-cultural tests of the FFM in over 50 societies across six continents have supported the existence and universality of the FFM (McCrae, 2002; McCrae, Terracciano, \& 78 Members of the Personality Profiles of Cultures Project, 2005; Schmitt et al., 2007). A universal structure suggests uniform covariance among traits in humans despite vastly different culture, history, economy, social life, ideology, and every other form of cultural and behavioral expression. The Big Five structure is even notable in captive chimpanzees, based on ratings by zoo employees (King \& Figueredo, 1997).

Despite the increasing consensus supporting the FFM, a five-factor structure does not robustly emerge everywhere, and some researchers have posited more than five personality factors within certain populations (e.g., Cheung \& Leung, 1998; Lee \& Ashton, 2004); however, these additional factors can often be subsumed under one of the Big Five factors (Guanzon-Lapeña, Church, Carlota, \& Katigbak, 1998). Thus, the FFM has yet to be robustly falsified, at least in literate, industrialized societies. If the FFM is a human universal and represents a "solid beginning for understanding personality everywhere" (McCrae \& Costa, 1997, p. 515), it should replicate everywhere and under a broad range of environments and populations. To date, the FFM has yet to be tested in an indigenous, preliterate society. The vast majority of samples from cross-cultural studies are often urban students, glibly referred to as western, educated, industrialized, rich, democratic (WEIRD) populations (Henrich, Heine, \& Norenzayan, 2010). Despite the wide range of cultures and languages where the FFM has been tested, WEIRD populations might show a similar personality structure if trait covariance is an artifact of living in large urban, literate populations. There are important reasons for assessing the validity of the FFM in an indigenous, preliterate society. First, human psychological adaptations likely evolved in the ancestral context of a hunting and gathering lifestyle with a social life characterized by frequent face-to-face interactions, largely with kin. Although pure hunter-gatherers are exceedingly rare, many groups maintain traditional lifestyles and share many social and economic characteristics with hunter-gatherers. Testing the FFM in these populations would be particularly valuable for assessing the universality of the FFM. In the past, empirical patterns observed in WEIRD populations and assumed to be human universals have been contradicted (or at least qualified) by observations in small-scale societies (Henrich et al., 2010). To date, no test of the FFM has ever been conducted among a small-scale population of foragers, farmers, or herders. 
Second, the existence of the FFM is an inductively derived success of personality psychology, but to date, no extensive theory exists that can generate the FFM from first principles. There are no a priori reasons for expecting a particular number of trait dimensions or within-trait and intertrait correlations, although post hoc explanations of empirical regularities have been made (e.g., Denissen \& Penke, 2008; Nettle, 2010). Thus, when the FFM receives less consistent support, as in several non-Western countries (e.g., Piedmont, Bain, McCrae, \& Costa, 2002; Schmitt et al., 2007; Triandis, 1997), a common response from FFM advocates is to argue that methodological issues prevent FFM replication. However, without a comprehensive theory of personality formation, it is unclear whether different socioecological environments should generate veritable differences in personality structure in the first place. Are the tenuous results in non-Western societies genuine or artifactual?

We provide the first test of personality structure among an indigenous, largely illiterate population: the Tsimane forager- horticulturalists of lowland Bolivia. We use a Spanish translation of the Big Five Inventory, a widely used metric of the FFM first developed by Benet-Martínez and John (1998). Our null prediction is that the Big Five should replicate in the Tsimane population. If certain features, such as literacy and education, are important for generating the Big Five pattern, we might find that the Big Five does not replicate among Tsimane. However, we should expect to find the Big Five structure to replicate among more educated and literate Tsimane. We test the validity of the five-factor model by assessing (a) internal reliability of each factor, (b) external validity of the factors, (c) 1-year test-retest factor correlations, (d) whether the FFM is generated from exploratory factor analysis, (e) whether confirmatory factor analysis supports the FFM, and (f) whether Procrustes rotation to a U.S-based sample indicates similar FFM structure. We determine whether the FFM is better replicated with $(\mathrm{g})$ stratification of the sample into subgroups that might differ in familiarity with testing procedures, performance, and self-reflection (age, sex, schooling, and Spanish fluency), (h) selective removal of least internally consistent items, (i) selective removal of items that evidence socially desirable responding (i.e., highly positive or negative response scores), (j) correction for acquiescence bias (i.e., a tendency of subjects to affirm personality descriptors read to them), or ( $\mathrm{k}$ ) evaluation of a separate sample of subjects asked to evaluate the personality of their spouses. Peer-reported personality may improve internal reliability of the Big Five (McCrae et al., 2005).

Despite our rigorous set of tests and analyses, we do not find strong, consistent support for the Big Five. We instead find evidence of factor structure consistent with a "Big Two" oriented around prosociality and industriousness. Our findings put the universality of the FFM into question but, more important, heighten the need to develop models of how loworder traits should be coordinated to assemble into higher order factors, given cultural and socioecological variability.

The paper is organized into five sections. Section 1 provides an overview of cross-cultural studies of the FFM in order to contextualize the value of the current study. Section 2 briefly describes the Tsimane population. Section 3 discusses our methods, and Section 4 presents our results. Section 5 interprets our results and discusses personality and the FFM in smallscale indigenous societies. 


\section{Cross-Cultural Studies of the Big Five}

The FFM has been assessed with both etic and emic approaches. In etic studies, a previously identified personality structure is applied in a different culture or context; in emic approaches, a personality structure is indigenously derived with a sampling of the target culture's personality descriptors.

The FFM was derived in English using a lexical (emic) approach, which assumes that all relevant personality descriptors are found in a group's vocabulary (Digman, 1990; Goldberg, 1990; John, 1990). Although early research in personality structure yielded many competing constructs to describe personality variation, the FFM has emerged as the most widely accepted model (Peabody \& De Raad, 2002). The FFM has since been tested in many countries and in numerous languages with the Revised NEO Personality Inventory (NEOPI-R) (Costa \& McCrae, 1992) and the Big Five Inventory (BFI) (Benet-Martínez \& John, 1998) protocols. Even a nonverbal protocol has confirmed the generalizability of the FFM in cross-cultural context (Paunonen, Ashton, \& Jackson, 2001).

Across cultures, etic studies have generally replicated the FFM (NEO-PI-R: McCrae, 2002; BFI: Schmitt et al., 2007), and factor scales show high internal reliability; however, Extraversion and Agreeableness are sometimes sensitive to "cultural effects" and are not always clearly differentiated (Ortiz et al., 2007; Rolland, 2002). As a result, McCrae, Costa, Del Pilar, Rolland, and Parker (1998) have suggested that a universal FFM consists of the first three factors and an "interpersonal circumplex"-which subsumes elements of Extraversion and Agreeableness factors based on Procrustes analysis (Rolland, 2002).

Among emic studies, an Openness factor is not consistently extracted (De Raad, 1994; Di Blas \& Forzi, 1998; Szirmák \& De Raad, 1994). Furthermore, several emic studies have consistently yielded more than five factors (Almagor, Tellegen, \& Waller, 1995; BenetMartínez \& Waller, 1997). In China, Cheung and Leung (1998) have identified a "tradition" factor independent of the Big Five. However, results from emic studies do not always match the results from etic studies of the same population. For example, in Italy, studies using translated inventories have identified a Neuroticism factor (Caprara, Barbaranelli, Borgogni, \& Perugini, 1993; Perugini \& Leone, 1996), but emic studies have not (Caprara \& Perugini, 1994; Di Blas \& Forzi, 1998). Openness and Neuroticism are more robustly established in etic studies than in emic studies, which has led to a growing consensus that lexical approaches underlying emic studies are not comprehensive ( Church \& Lonner, 1998; Rolland, 2002). As McCrae and Costa (1997) concluded, "It is simply not the case that all personality traits are encoded as adjectives ... lexical studies confound differences in personality structure with differences in personality language" (p. 510).

In cross-cultural studies, reliability of the FFM has been highest in developed countries. In Allik and McCrae (2004) and Schmitt et al. (2007), sample populations were predominantly college students and were often bilingual. In developing countries, the FFM has met with less success; whether this is due to methodological problems or to actual differences in personality structure remains to be determined. Methodological differences may arise due to translations not being equivalent, lack of item relevance in the local culture, differences in 
subject response styles, unfamiliarity with the test format, and unrepresentative samples (Paunonen \& Ashton, 1998).

In Schmitt et al. (2007), internal consistency of factor items based on Cronbach's alpha was sufficiently high in South American samples, with each country averaging above the standard benchmark of 0.70. However, several African countries fared worse: Average Cronbach's alphas for Morocco, Tanzania, Ethiopia, and Congo were 0.62, 0.59, 0.48, and 0.48 , respectively. Despite low internal consistency, the African and South American samples showed high levels of congruence with the American normative factor structure under Procrustes rotation (Schmitt et al., 2007). However, of the seven countries in Africa reported in Schmitt et al. (2007), six were administered the BFI in English, and four had samples restricted to college students. Similarly, the five South American countries in the study (including Bolivia) contained only college students.

Reliability is sometimes improved in studies that rely on third-party observer reports rather than self-reports. In a large cross-cultural study of this type in 50 different societies, McCrae et al. (2005) asked college students to give observer ratings on the NEO-PI-R for persons of all ages they knew well. Roughly $5 \%$ of the Cronbach alphas were lower than 0.70 , with this $5 \%$ concentrated primarily in the samples from developing countries. Although relying on observer ratings helped improve internal consistency, it did not eliminate potential problems of evaluative bias common to self-report data in developing societies. For example, Openness did not cleanly emerge in Nigeria. McCrae et al. (2005) concluded that "it is possible that there is a minority of cultures in which the [FFM] structure is not found" (p. $552)$.

To our knowledge, only two studies have focused explicitly on ethnic populations in the developing world. Piedmont et al. (2002) tested the NEO-PI-R among the Shona, a subSaharan society in Zimbabwe. Within this mixed rural and suburban sample (predominantly college students bilingual in English and their native Shona), the average internal consistency for the five factors was 0.77, higher than for the African samples in Schmitt et al. (2007). However, Openness produced a low reliability of 0.64 , and only five of the 30 NEO-PI-R facets produced reliabilities above 0.60. Factor congruence with the American normative structure was high at 0.89 , but only 15 facets produced congruence coefficients higher than 0.90. These results were obtained with the Shona language version of the NEOPI-R; the English version of the test showed slightly higher reliability and congruence. Schmitt et al. identified translation problems as the main factor contributing to the less than ideal fit to the FFM: The Shona language lacks words equivalent to some of the English terms in the NEO-PI-R.

Alvergne, Jokela, and Lummaa (2010) administered the English Mini-Markers Big Five Inventory (Thompson, 2008) in four agricultural Senegalese communities, among individuals with diverse ages and with low levels of education. The subsistence focus on cash cropping and the low fertility rate (5 births per woman) are not characteristic of more traditional human societies lacking agriculture and practicing natural fertility. The sample size was quite small ( $n=65$ families), and the Mini-Markers Inventory used has not been validated among non-English speakers. After removal of hard-to-translate items and further 
shortening of the survey for brevity, the administered version of the BFI included only 27 items. Alvergne et al. retained about half of those items for analysis, with most factors based on only two or three adjectives. Reliability among these factors was still low, averaging 0.64 .

\section{Study Population}

The Tsimane are forager-horticulturalists of central lowland Bolivia, located along the Maniqui, Quiquibey, Apere, and Matos Rivers and in adjacent forests of the Beni Department. Although families may spend weeks or months on hunting or fishing trips or cultivate fields some distance from their primary house in settled villages, the Tsimane are semisedentary and live in communities ranging from 30 to 500 individuals. Their population is estimated at 10,000 and is dispersed among over 90 villages. They cultivate plantains, rice, corn, and sweet manioc in small swiddens and regularly fish and hunt for meat. These foods together provide over $90 \%$ of the calories in the diet, with the remainder coming mainly from trade with itinerant merchants. Polygyny occurs at low frequencies $(\sim 5 \%)$ and is concentrated in more remote communities (Gurven, Winking, Kaplan, von Rueden, \& McAllister, 2009). Exclusive priority of access for individuals or small groups to certain rights and resources is minimal, but land close to village centers is de facto privately owned. More extensive ethnographic background can be found in Chicchón (1992), Huánca (1999), and Schniter (2009).

Since the mid-20th century, the Tsimane have come into greater contact with modernizing influences. In Tsimane villages, especially those located near the town of San Borja (population 25,000 ), incipient cattle ownership, wage labor with loggers and farmers, and produce sales to local markets are on the rise. Many Tsimane now have minimal access to health care through the services of a health post, a hospital in San Borja, and the Tsimane Health and Life History Project, but mortality rates remain high, particularly among infants. Approximately $20 \%$ of offspring never reach age 5 (Gurven, Kaplan, \& Zelada Supa, 2007). The Tsimane rarely use modern contraceptives; the total fertility rate is very high ( $\sim 9$ births per woman), and so the population growth rate is high (3.6\% per year). Many Tsimane villages now have access to public schooling for their children taught largely by bilingual Tsimane teachers trained by local missionaries. Several secondary schools now exist in larger villages, and young Tsimane adults are starting to become high school graduates. However, the overall adult literacy rate remains low, at $25 \%$. Fluency in the native Tsimane language is universal, and only $40 \%$ of adults are moderately fluent in Spanish. The Tsimane language is an isolate, together with Mosetene, and it is unrelated to the dominant indigenous languages of Bolivia.

Tsimane live in extended family clusters, within which occur the majority of food and labor sharing. Although social and cooperative in daily interactions with village co-residents, Tsimane families value their autonomy. Groups of family clusters compose villages, which were given formal geographic boundaries only in the late 20th century and lack a strong sense of identity (Gurven, Zanolini, \& Schniter, 2008). Village residents elect chiefs to organize community meetings and to represent their interests to outside political bodies, but chiefs lack any substantial authority, tend to have short tenure, and often are unable to 
effectively organize people for collective action (Gurven \& Winking, 2008; von Rueden, Gurven, \& Kaplan, 2008). In the event of interpersonal conflict, Tsimane often "vote with their feet" by moving to other villages.

Tsimane often describe each other in valent terms, with judgments of good (jäm'si) and bad (jam jäm'si or a'chis) applying to numerous domains. Maintaining friendly relations (jäm'yity muntyi), being easygoing (chuchuijtyi), and avoiding direct confrontation and expression of anger (chij facoij) are viewed as proper ways of behaving and are ingrained in Tsimane culture. In their descriptions of others, Tsimane recognize the persistence of particular traits in individuals over time. Someone who speaks freely (chij peyaquity) but not too much or in a gossiping way (chij peyacsity) is a valued social partner, and jokesters are also recognized and viewed positively (chij shevinyity). Happy, cheerful individuals (majoijbäyis) are contrasted with serious, quiet individuals (futy'dyety) or those who are easily annoyed (achiyity). Other negative traits commonly described refer to those who react rapidly, usually in a bad way (che'chei'si), those who brag (va'bunyis), and those who are lazy (shoyijyi'tyi or jamyedyedyetyi). Laziness is often contrasted with demonstration of strong work effort (setyi or chij carijtaqui) and generosity in helping others (chij notacsity).

\section{Method}

We administered a personality questionnaire based on the Big Five Inventory (BFI), a widely used 44-item metric of the five-factor model. The Spanish version of the BFI, previously validated by Benet-Martínez and John (1998), was translated into the Tsimane language by two bilingual Tsimane research assistants (Marino Lero Vie [MLV] and Feliciano Cayuba Claros) and Michael Gurven (MG). As a test of the accuracy of the translation, the Tsimane questionnaire was then back-translated into Spanish by a different translator, and discussions among the three bilingual Tsimane and MG ensued until a workable translation was found that captured the essence of each item. Due to limitations of Tsimane vocabulary, several items required a definitional phrase in the local idiom rather than relying on a single word to capture the right meaning. In these cases, either an exact word did not exist or, taken out of context, the word could be misconstrued. For example, Item 31 ("is clever and analytical") was translated as Mi buty chij cave'jedye judyeya jäm' yu' ban mi (literally, "Knows how to 'see' things and can make things turn good"), because the Tsimane word for "smart" reflects the state of being knowledgeable. Item 32 ("radiates enthusiasm") was translated as Mi buty fer ma'je' ji'cave' jun'si chuc mi ma'je (literally, "You really show to others whatever it is you want" [to show]) because there are no Tsimane words for "radiate" or "enthusiasm." Due to the lack of any word for "art" in Tsimane, Item 44 ("few artistic interests") was translated more descriptively as "someone who does not like to play music, sing, tell stories, or draw." Those are the main forms of artistic expression in Tsimane society. When necessary, translating the whole concept rather than the literal words enabled us to circumvent translation problems reported by other crosscultural studies of the FFM (e.g., Piedmont et al., 2002). Only one item from the original BFI was removed (Item 30: "has an active imagination") due to the inability to find a suitable expression to explain the concept in a manner that was consistently understood by Tsimane subjects. This item, alone among the BFI items, was found to be understood differently by bilinguals when presented in Spanish versus English, suggesting it should be 
revised or omitted from the BFI in the context of cross-cultural studies (Ramírez-Esparza, Gosling, Benet-Martínez, Potter, \& Pennebaker, 2006). Thus, the final Tsimane BFI instrument includes 43 items.

The Tsimane BFI was administered to 632 adults from 28 villages during the period January 2009 to December 2010. The sample was $48 \%$ female, the average age was 47 years (range $=20-88$ years, $S D=14.4$ ), and the average years of formal education was 1.2 years (range $=$ $0-12$ years, $S D=2.2$ ). The age, years of formal education, and Spanish proficiency of all subjects were ascertained from demographic interviews (see Gurven et al., 2007). The Tsimane BFI was conducted verbally in a private location by a bilingual Tsimane research assistant (MLV) trained in the administration of anthropological and psychological interviews. As in the English version of the BFI, responses were given on a translated scale where 1 corresponds to strongly disagree and 5 corresponds to strongly agree. Subjects were first given a quick tutorial and comprehension test on the use of the scale, after which all subjects showed clear evidence of understanding the scale and the task at hand. The scale, depicted on a piece of cardboard placed in front of the subject, included drawings to help facilitate understanding. Five drawings of a person accompanied the five numbers on the scale; the drawings revealed more and more of the person as the scale ascended: a drawing of just a person's legs accompanied 1 and a drawing of the whole body accompanied 5. Although many respondents were previously unfamiliar with Likert-type scales, few were new to formal interviews because of their extensive participation in the Tsimane Health and Life History project we have maintained continuously since 2002 (see http://www.unm.edu/ tsimane/). Indeed, our decade-long presence in the area has helped to establish trusting, collaborative relationships among study subjects.

After the interview, MLV used the same 5-point scale to rate respondents on four variables based on his observations during the fifteen or so minutes of the BFI interview together with an additional 30 minutes spent conducting a separate interview (on economic production and sharing): the extent to which the subject was talkative, shy, smiling and/or joking, and easily distracted. These were added to help gauge external validity of the FFM instrument. MLV performed multiple test runs in order to ensure consistency in his observations.

None of our interviews produced missing items. Thirty-four subjects (53\% female) were interviewed twice, each interview roughly a year apart (average $14.2 \pm 2.6$ months), providing a test of response stability. The average age of this subsample is 52 years.

In addition to conducting our first-person interviews, we asked 430 Tsimane adults to rate their spouses on the Tsimane BFI. These interviews were conducted during the period from March 2011 to February 2012. The sample of spouses who were rated was 50\% female, and the average age was 52 years (range $=16-89$ years, $S D=11.6$ ). The protocol did not differ from the self-report protocol except that with each item of the BFI verbalized to the raters, subjects were reminded to evaluate their spouse. The self-report and spouse-report samples overlap for 66 individuals ( $46 \%$ female; average age $=52$ years). Although the spousereport sample by definition excludes unmarried individuals, we do not expect significant differences across the samples due to marital status: Only 26 of the 632 adults in the selfreport sample were single at the time of data collection. 


\section{Results}

\section{Internal Reliability}

We first test the reliability of each of the Big Five factors. The Cronbach's alpha measures of internal reliability, factor means, ranges, and standard deviations are given in Table 1. All items phrased in reverse (e.g., the Extraversion item "is shy") were reverse scored prior to calculation of these statistics. Although the distributions of subjects' scores on the Big Five factors do not conform to a normal distribution according to the Shapiro-Wilk test, the distributions do not exceed skew or kurtosis values of \pm 1 . Extraversion, Agreeableness, Conscientiousness, and Openness show moderate internal reliability (Cronbach's $\alpha=0.63$, $0.58,0.69$, and 0.54 , respectively), and Neuroticism shows low reliability (0.31).

\section{Internal Reliability by Age, Sex, Education, and Spanish Fluency}

We next examine whether internal reliability differs by age, sex, formal education, and Spanish fluency. If schooled adults are more familiar with testing and if Spanish speakers are more familiar with other ideas and cultures in a way that may promote self-reflection, then their item responses within factors might be more consistent than responses from unschooled or monolingual Tsimane speakers. Subjects were divided into several subgroups: those older and younger than 44 years (the median age), men and women, those with and without any formal schooling, and those who do or do not speak Spanish. Although internal reliability of several of the Big Five improves within particular subgroups, no subgroup shows consistent improvement across all of the Big Five (see Table 2). Averaged across the Big Five, differences in reliability between complementary subgroups (e.g., old vs. young) were close to zero. Extraversion and particularly Openness show higher internal reliability among men, the young, the educated, and those who speak Spanish. Agreeableness and Conscientiousness produce the opposite result.

\section{Removing Potentially Problematic Items and Correcting for Acquiescence Bias}

We consider the possibility that despite our efforts at repeated translation and backtranslation, certain items may still have been interpreted differently by subjects from their intended meaning. If certain items are driving the low reliability scores, we might expect them to load weakly on each factor. In an attempt to address this potential problem, we first drop the least reliable item (i.e., the item whose removal would most increase factor internal reliability) from each of the Big Five and recalculate Cronbach's alpha. Extraversion and Conscientiousness now surpass the standard benchmark of 0.70 , and internal reliability for Agreeableness and Openness improve but remain suboptimal. The reliability for Neuroticism remains quite low even after removal of the least reliable item (see Table 1). The least internally reliable items include, for Agreeableness, Item 22 ("is sometimes illmannered with others"); for Conscientiousness, Item 42 ("gets distracted easily"); for Extraversion, Item 6 ("is reserved"); for Neuroticism, Item 35 ("remains calm in difficult situations"); and for Openness, Item 12 ("likes routine"). Further removal of the weakest remaining item from each factor did not bring Agreeableness, Neuroticism, or Openness to acceptable levels of reliability. 
The first and second least reliable items within each of the Big Five are all items that are reverse scored. This suggests these items may have been differentially susceptible to socially desirable responding. Alternatively, a low covariation among true- and reverse-scored items within each of the Big Five could arise through acquiescence bias, which is any tendency of individuals to respond affirmatively to questions posed them. We remove all reverse-scored items and recalculate Cronbach's alpha for each of the Big Five. This eliminates 16 of the 43 items. Agreeableness, in addition to Extraversion and Conscientiousness, now produces acceptable internal reliability. The reliabilities for Neuroticism and Openness remain low (see Table 1).

We next assess internal reliability by removing other items that may have prompted socially desirable responding. These are items with high or low mean response values. Given the self-report nature of the BFI instrument, especially to a third-party (albeit neutral) Tsimane assistant, it may be that an individual less familiar with interviews (a) is uncomfortable conveying self-ratings for traits deemed highly negative or (b) gives biased responses for highly positive traits when speaking to another Tsimane (or even to him- or herself). We therefore remove items with mean response scores less than two or greater than four. This eliminates nine of the 43 items: two with strong disagreement (Item 2: "tends to be critical"; Item 13: "starts disputes with others") and seven with strong agreement (Item 3: "is meticulous about work"; Item 10: "has diverse interests"; Item 11: "energetic"; Item 23: "is inventive"; Item 26: "worries about things"; Item 35: "maintains calm in difficult situations"; Item 37: "is considerate and friendly with everyone"). This exercise modestly increases internal reliability for Neuroticism yet decreases reliability for Agreeableness, Openness, Extraversion, and Conscientiousness (see Table 1). Thus, with this manipulation, none of the Big Five surpass a Cronbach's alpha score of 0.70. It is noteworthy to mention that for at least five of these eliminated items, means distant from 3 are unsurprising and mesh with our expectations based on 12 years of experience living with Tsimane.

Finally, we attempt to correct for acquiescence bias not by removing problematic items but according to the method described in Hofstee, Ten Berge, and Hendriks (1998). First, we average the response scores for each subject for 15 BFI item pairs with opposite implications for personality (Soto, John, Gosling, \& Potter, 2008). Second, we generate an acquiescence index by calculating the difference between each average and the scale midpoint. Third, we subtract each subject's acquiescence score, whether positive or negative, from his or her responses. The average acquiescence score across the 632 subjects is $0.23(S D=0.29)$, which is $5.84 \%$ of the scale range. Acquiescence in Western subjects is of a similar magnitude: Rammstedt, Goldberg, and Borg (2010) reported an average acquiescence score on the BFI of $0.11(S D=0.28)$ for German adults with a high degree of formal education and an average score of $0.25(S D=0.38)$ for those with little or no formal education. Among the Tsimane, correction for acquiescence bias generates acceptable internal reliability only for Conscientiousness. Internal reliability decreases significantly for Openness (see Table 1). 


\section{External Validity}

The Big Five are correlated in expected directions with observed characteristics of subjects during interviews (see Table 3). Extraversion, Agreeableness, Conscientiousness, and Openness are positively correlated with smiling and negatively correlated with shyness. They also positively correlate with talkativeness and negatively correlate with distractedness, but the effect sizes are smaller. Neuroticism is positively correlated with the respondent's shyness and negatively correlated with smiling.

\section{Response Stability}

Test and retest responses were collected about a year apart from 34 subjects. The Tsimane average retest correlation (Spearman's rho) is 0.431 and ranges from 0.274 ( $p=.116$, twotailed) for Agreeableness, $0.370(p=.031)$ for Neuroticism, $0.420(p=.013)$ for Openness, $0.466(p=.005)$ for Conscientiousness, to $0.627(p<.001)$ for Extraversion.

\section{Correlations Between Factors}

Spearman correlations among the Big Five are presented in Table 4. All correlations are significant at the $1 \%$ level. Neurotic individuals are less likely to be extraverted, agreeable, open, and conscientious. All other associations among other factors are positive. Extraversion is especially highly correlated with each of the other Big Five.

\section{Exploratory Factor Analysis}

We perform an exploratory factor analysis (EFA) using varimax rotation and principalcomponents extraction to test whether our $43 \mathrm{BFI}$ items inductively organize into the familiar Big Five. The unrestricted EFA results in 11 components with eigenvalues greater than one, and the eigenvalues decrease sharply after the first component (see Figure 1).

Before factor rotation, the first factor explains $20.8 \%$ of the variance in the data, and the second factor explains only $5.2 \%$ of the variance. After factor rotation, this disparity is attenuated: The first factor explains $13.2 \%$ of the variance, the second explains $9.8 \%$, and the third through fifth factors explain approximately $4.0 \%$ of the variance each. The rotated component matrix shows considerable cross-loading of items from the BFI, with no clear replication of any Big Five factor (see Table S1 of the supplemental materials). Only the first and second factors are well defined based on the intercorrelations of items that load the highest on each factor. Cronbach's alpha is 0.88 for the first factor, 0.83 for the second factor, and $<0.55$ for subsequent factors in the unrestricted EFA. Restricting the EFA output to five factors does not noticeably improve replication of the Big Five (see Table 5).

Stipulating a five-factor structure, we perform several EFAs with different subsets of the BFI items, with different subject subgroups, and with the data corrected for acquiescence bias. We (a) remove the 16 reverse-scored items; (b) remove items that may have prompted socially desirable or norm-conforming responses, as determined by item mean response scores of more than four or less than two; (c) transform the data to account for subjects' degree of acquiescence bias; and (d) split the data by sex, age, schooling, and Spanish fluency. None of these manipulations clearly indicate a Big Five factor structure as determined by the rotated component matrices (see Tables S2-S12 of the supplemental 
materials), and all exhibit a large first component that, prior to factor rotation, explains on average 3.2 times more of the variance in the data than the second component. Most Extraversion items load highly on the first derived factor, in addition to items from each of the other Big Five. Comparison of the items composing the derived factors (Tables 5, S2S12) reveals a similar personality structure across most EFA subsets. Removing reversescored items (Table S2) and correcting for acquiescence (Table S4) produce factors suggestive of Agreeableness and Conscientiousness. However, many of the Agreeableness and Conscientiousness items continue to load highly on more than one factor. An EFA restricted to true-scored items from Extraversion, Agreeableness, and Conscientiousness comes closer to replicating those factors (see Table S13 of the supplemental materials).

\section{Confirmatory Factor Analysis}

We use maximum likelihood estimation to test the fit of the self-report sample $(n=632)$ to the FFM in a confirmatory factor analysis (CFA). The estimated model contains 96 free parameters, including 10 covariances among the Big Five latent variables, 38 paths from the latent variables to the observed BFI items, and 48 variances. Model fit is poor: $\chi^{2}(850, N=$ $632)=2,695.247, p<.001$; root-mean-square error of approximation $($ RMSEA $)=0.059$, 90\% CI [0.056, 0.061]; comparative fit index $(\mathrm{CFI})=0.716$; Akaike information criterion $(\mathrm{AIC})=2,887.247$. We also perform a CFA with the 16 reverse-scored items removed, given their negative effects on internal reliability of the Big Five, particularly Extraversion, Agreeableness, and Conscientiousness. Model fit is improved but still a poor match to the data: $\chi^{2}(314, N=632)=1,086.643, p<.001 ;$ RMSEA $=0.062,90 \%$ CI $[0.058,0.067) ; \mathrm{CFI}$ $=0.823 ; \mathrm{AIC}=1,214.643$.

\section{Procrustes Rotation}

Standard protocol for assessing the comparability of personality structure across two populations involves a Procrustes rotation of sample data and estimation of factor congruence with another population that strongly displays the Big Five (McCrae, Zonderman, Costa, Bond, \& Paunonen, 1996; Piedmont et al., 2002; Schmitt et al., 2007). Despite our inability to reveal the Big Five using EFA or CFA, we consider the possibility that Tsimane personality structure may nonetheless be statistically similar to that in samples that typically do. We use Procrustes analysis to determine the factor congruence between our sample and a target structure, in this case a U.S. sample ( $n=2,793$ college students, 64\% female) from Schmitt et al. (2007). McCrae et al. (1996) showed that Procrustes analysis is a more accurate test of replication than confirmatory factor analysis. It has since been used to successfully replicate the Big Five model within several novel samples (e.g., Piedmont et al., 2002; Schmitt et al., 2007). Congruence scores above 0.90 are indicative of good fit (McCrae et al., 1996). As shown in Table 6, Conscientiousness has the most congruence with the U.S. sample, and Neuroticism produces the least congruence. Although congruence does not improve to acceptable levels when using any of the subsamples described in previous sections, removing reverse-scored items from each of the Big Five does improve congruence (see Table 6). Splitting the data by age or sex does not notably improve congruence within any of the subgroups. Performing the same analysis on the loadings derived from the educated and Spanish-speaking subgroups actually decreases congruence for most factors. Removal of items with high and low average response scores 
and correction for acquiescence bias produce significant increases in congruence only for Neuroticism.

\section{Comparison With Spouse Reports}

Finally, we assess whether spouse-reported personality improves replication of the Big Five among the Tsimane. Internal reliability of the Big Five is lower than in the self-report sample (see Table 1). Cronbach's alpha scores do not climb above 0.70 even after removal of the least reliable item within each factor, removal of reverse-scored items, removal of items with average scores more than four or less than two, and correction for acquiescence bias. The exception is Conscientiousness, which reaches acceptable internal reliability with removal of reverse-scored items.

Exploratory factor analysis using varimax rotation and principal-components extraction produces 11 factors with eigenvalues greater than one. There is less disparity in variance explained between the first and second factors than in the self-report sample (see Figure 1). Before factor rotation, the first factor explains $17.5 \%$ of the variance in the data and the second factor explains $10.5 \%$ of the variance. After factor rotation, the first factor explains $10.4 \%$ of the variance, the second $10.2 \%$, the third $7.0 \%$, the fourth $4.4 \%$, and the fifth factor $4.2 \%$ of the variance. As with the self-report sample, the rotated component matrix shows considerable cross-loading of items from the BFI, and internal consistency is high for only the first two factors (see Table S14 of the supplemental materials). Cronbach's alpha is 0.85 for the first factor, 0.81 for the second factor, and $<0.65$ for subsequent factors. Restricting the EFA output to five factors does not improve replication of the Big Five (see Table 7).

Procrustes analysis does not indicate factor congruence with a U.S. sample that strongly displays the Big Five (see Table 6). Conscientiousness has the highest congruence coefficient at 0.72 , and Neuroticism produces the lowest congruence coefficient at 0.38 . Average congruence is lower than for the self-report sample.

We use maximum likelihood estimation to test the fit of the spouse-report data to the FFM in a CFA. The estimated model contains 96 free parameters, including 10 covariances among the Big Five latent variables, 38 paths from the latent variables to the observed BFI items, and 48 variances. Model fit is poor: $\chi^{2}(850, N=431)=3,126.172, p<.001$; RMSEA $=0.079,90 \% \mathrm{CI}[0.076,0.082] ; \mathrm{CFI}=0.523$. Akaike information criteria indicate that the self-report data ( $\mathrm{AIC}=2,887.247)$ is a better fit than the spouse-report data $(\mathrm{AIC}=$ $3,404.172)$ to the FFM.

\section{Big Two?}

As we report above, only the first two factors from the self- and spouse-report samples exhibit high internal reliability in an unrestricted EFA, based on the items that load the highest on each derived factor (see Tables S1 and S14 of supplemental materials). Given the low intercorrelations of the items within factors beyond the first two, we consider these factors poorly defined (see Tabachnick \& Fidell, 2001). A scree test corroborates the 
emergence of only two well-defined factors in the spouse-report sample but is more indicative of a single factor in the self-report sample (see Figure 1).

Using Procrustes analysis, we test congruence between the unrestricted EFA solutions for the self- and spouse-report samples. Congruence between the second self-report factor and the first spouse-report factor is high (0.91); seven of the eight items that load the highest on the latter also load the highest on the former (see Tables S1 and S14 of supplemental materials). Congruence is also high (0.89) between the first self-report factor and the second spouse-report factor, though this is nonobvious from comparison of Tables S1 and S14. Only four of the items that load the highest on the second spouse-report factor load the highest on the first self-report factor. However, congruential rotation takes advantage of the fact that the additional items loading highly on the first self-report factor show considerable cross-loading across the spouse-report derived factors. Subsequent factors from the selfreport data produce lower congruence with the spouse-report factors, with coefficients ranging from 0.70 to 0.34 .

We find significant response stability for the first two derived factors, based on the 34 individuals who self-reported their personality in 2009 and again a year later. To generate individuals' scores on a particular derived factor, we used least squares regression. The retest correlation (Spearman's rho) is $0.741(p<.001)$ for the first derived factor and 0.361 $(p<.036)$ for the second derived factor.

The items composing the first two derived factors include traits from all Big Five factors, although Extraversion and Agreeable-ness items load more highly on one factor, whereas Conscientiousness items load more highly on the other (see Table 5 and S1 of the supplemental materials). The Spearman correlation between the two factors is 0.019 ( $p=$. 640).

\section{Discussion}

Evidence for the five-factor structure of personality among the Tsimane of Bolivia is weak. Internal reliability is generally below levels found in developed countries. The five-factor model did not cleanly emerge in any of the exploratory or confirmatory factor analyses, and Procrustean rotations did not produce strong congruence with a U.S. sample. Procrustes analysis, which is arguably the most forgiving test for replication of the FFM (McCrae et al., 1996), yielded an average congruence coefficient of 0.62 . This is well below the benchmark of 0.90 and considerably less than most congruence scores found in other cross-cultural applications of the Big Five (McCrae et al., 2005; Schmitt et al., 2007).

We were able to discount several possible explanations for our results. First, we found no significant differences in structure replication after stratifying the sample by education level, Spanish fluency, sex, or age cohort. Despite research showing that education increases abstract reflection as measured by IQ (e.g., Ceci, 1991), educated and Spanish-speaking subsamples did not produce better replication of the Big Five among the Tsimane. Younger individuals (who are also more educated and more fluent in Spanish) were no more likely than older adults to display the Big Five. Similarly, men (who are also more educated and 
more fluent in Spanish) were no more likely than women to display the Big Five. These results are not surprising, in light of the fairly limited variation in Tsimane lifestyles and participation in traditional village life. Even the youngest and most educated Tsimane remain deeply embedded in traditional practices of food production and social exchange within their villages, which may partly explain why we find minimal differences in factor structure across these subsamples.

Second, removal of items with high or low average response scores did not improve replication of the Big Five relative to the full set of BFI items. Approximately one quarter of the items in the Tsimane BFI produced average responses below two or above four; these items may have elicited more socially desirable responding than other items. Studies that claim evidence for one or two higher order personality factors (e.g., Digman, 1997; Musek, 2007) have been interpreted as artifacts of socially desirable responding (Bäckström, Björklund, \& Larsson, 2008; McCrae et al., 2008). However, removal of items with low and high average response scores did not produce any closer fit to the FFM.

Third, a correction for acquiescence bias did not provide better support for the FFM. Acquiescence bias is indicated by inconsistent responding to items describing similar personality traits (Hofstee et al., 1998) and has been linked with lower educational attainment (Narayan \& Krosnick, 1996; Rammstedt et al., 2010). However, our correction for acquiescence bias did not improve internal reliability of the Big Five or produce a significantly better overall fit to the FFM in EFA or Procrustes analysis.

Fourth, removal of reverse-scored items improved fit to the FFM in confirmatory factor analysis, but the fit remained poor. The reverse-scored items were the least consistent items within the Big Five, suggesting they were differentially susceptible to response biases. With the reverse-scored items removed, Extraversion, Agreeableness, and Conscientiousness just exceeded the threshold for acceptable internal reliability, and they showed clearer differentiation in exploratory factor analysis. However, items composing these factors continued to load highly on more than one factor, and Extraversion and Agreeableness items retained substantial covariation. Congruence with a U.S. target structure was higher than with our other subsamples but remained well below the benchmark of 0.90 .

Fifth, we find that subjects' personality as reported by their spouses does not support the FFM. Compared to self-report, peer report may be less influenced by response styles and has been shown to increase internal reliability among the Big Five (McCrae et al., 2005; Riemann, Angleitner, \& Strelau, 1997). Among the Tsimane, however, spouse-reported personality produced a worse fit than did self-reported data to the FFM, based on tests of internal reliability, EFA, CFA, and Procrustes congruence analysis with comparison to a U.S. target structure.

Additional evidence supports the lack of the FFM among the Tsimane. Retest correlations amongst the 34 Tsimane respondents sampled twice are significant for all Big Five factors but Agree-ableness. However, the average retest value of 0.415 is substantially lower than the $\sim 0.65$ median retest correlation for the Big Five in Western adult samples (Costa \& 
McCrae, 1994). Furthermore, Agreeableness produced the lowest retest correlation even though Neuroticism and Openness fared worse in tests of internal reliability.

We find relatively high significant correlations across the Big Five (see Table 4), of higher magnitude than typically found in populations where the Big Five is evident. Thus, even though we find evidence that responses to the Tsimane BFI show external validity with observed characteristics of subjects, these observations are correlated across all Big Five factors. For example, Tsimane individuals who score higher in Neuroticism are observed to be more shy and to smile less. Individuals who score higher in Extraversion are observed to be less shy and to smile more often. However, these observations of extraverts also characterize individuals who score higher in Agreeableness, Conscientiousness, and Openness. Our evidence of external validity is therefore less indicative of the FFM than other factor structures.

A valid test of the Big Five requires both that the survey items were translated accurately and that the items bear similar cultural meaning in the target society. The care with which we translated and retranslated the BFI may not preclude culture-specific interpretations of some of the items. For example, the Extraversion item "is reserved" may have been interpreted less as taciturn and more as modesty. The BFI's reliance on dispositional terms without reference to specific situations contributes to such differences in interpretation. Successful survey instruments developed in research among Tsimane and similar groups often require concrete questions with sufficient background details (e.g., On a scale of 1-7, "how often do you hunt?" will generate more confusion and misleading responses than "In the past seven days, how many of those days did you go hunting?"). Although adding specificity to each BFI item may limit the ability to capture broader aspects of personality dimensions, it may ensure greater reliability and more meaningful responses (see Denissen $\&$ Penke, 2008). On the other hand, the Tsimane often speak of their peers' personalities in the abstract (see our description of the study population), so we do not anticipate that context-specific personality items will necessarily reveal a different personality structure than manifested with our current data.

Exploratory factor analysis yields a personality structure that is largely distinct from the Big Five. Unrestricted, the factor analysis yields 11 derived factors with significant eigenvalues. When restricted to five factors, the derived factors each subsume items from at least four of the Big Five. The first derived factor is largely a mix of Extraversion and Agreeableness items and reflects a general prosocial disposition. "Reserved" and "talkative" both load positively on the first factor, but this is not necessarily contradictory. Respondents likely interpreted "reserved" as not boasting, rather than being taciturn. An egalitarian ethic among the Tsimane often curtails verbal expression of personal achievement, as is the case in many small-scale societies (Boehm, 1999). The Tsimane esteem individuals who talk confidently but modestly in public settings. The Openness items "original" and "ingenious" also load positively on the first derived factor, which suggests prosocial individuals are also the most creative.

Several items from Conscientiousness sort on the second derived factor, including "efficiency," "perseverance," and "thoroughness." "Energetic" and "inventive" also load 
highly on this factor. These items may reflect industriousness in the context of subsistence labor. Because food production labor is pooled within Tsimane extended families, it is helpful to our interpretation that "unselfishness" and "reliability as a worker" also load highly on the second factor. The third derived factor subsumes undesirable traits, whether in the context of social gatherings or labor. The fourth and fifth derived factors are more difficult to interpret and also show the least internal consistency. "Calm in tense situations" and "quiet" load positively and "quarrelsome" loads negatively on the fifth factor, which may reflect deference or reservedness in social situations. The fourth derived factor includes the items "finds fault," "moody," "easily distracted," and "curious," which is suggestive of the Western notion of (teenage) angst or, as communicated by a reviewer, an imaginative personality thwarted by a conservative society. However, these four items come from four different factors (Agreeableness, Neuroticism, Conscientiousness, and Openness, respectively).

The internal reliability of the first two derived factors in Table 5 (five-factor solution) and Table S1 (unrestricted factor solution) is high, supporting the possibility of a "Tsimane Big Two" organized according to prosociality and industriousness, as described above. These two factors show significant response stability; response stability for the first derived factor is stronger than for any of the Big Five. The spouse-report sample also produces two factors that explain more of the variance and are more internally consistent than the other derived factors. Furthermore, congruence between the self- and spouse-report samples on these first two derived factors is high. The Tsimane Big Two are therefore consistent across both selfand spouse-report samples. However, these Big Two are not the two higher order factors of Digman (1997), characterized as stability and plasticity by DeYoung (2006), which neatly subsume the Big Five by merging Extraversion with Openness and Agreeableness with Conscientiousness and Neuroticism. Our factors instead cut across the Big Five domains. These results are consistent with the findings of Ashton, Lee, Goldberg, and de Vries (2009), where higher order factors emerge because lower order facets load onto multiple factors. Not only do we find that items load onto multiple factors, but the loading coefficients in our exploratory factor analyses are generally lower than those found in previous studies of the Big Five.

Our findings provide evidence that the Big Five model does not apply to the Tsimane. Our findings also bring into sharper focus past reports from developing societies where the FFM was not clearly replicated. Of the 50 countries reported in McCrae et al. (2005), only India, Morocco, Botswana, and Nigeria produced average congruence scores less than 0.90 . The lowest congruence scores reported by McCrae et al. are 0.53 and 0.56 for Openness in Botswana and Nigeria, respectively. In the African and South Asian countries from Schmitt et al. (2007), internal reliability for Extraversion, Agreeableness, and Conscientiousness is similar to what we report for the Tsimane. Because the samples from the developing countries in Schmitt et al. and McCrae et al. are primarily college students, more representative samples from these countries may have produced even lower congruence scores and internal reliability.

If the Big Five (or any other number of fixed traits) are not pan-human universals, then what could explain variability in personality structure? Nettle (2010) argued that personality items 
covary because they act synergistically. For example, he suggests that the fitness payoff to ambition is positive if sociability is also high; these traits thus covary as part of the Extraversion continuum. Similarly, the fitness payoff to imagination is positive if intellect is also high; thus, both traits covary along the Openness continuum. If the synergism of particular personality traits has different fitness consequences in different socioecological environments, we may not expect a universal structure of personality covariation. Behavioral genetic data support this possibility: Two independent dimensions of genetic variance are necessary to explain variation in each of the Big Five factors (Jang, Livesley, Angleitner, Riemann, \& Vernon, 2002). In different socioecologies, these independent genetic sources may not contribute to the same behavioral dispositions or experience parallel selection pressures (Penke, Denissen, \& Miller, 2007).

Variation in personality structure across populations need not derive from different patterns of covariation among genetic polymorphisms. Instead, different personality structures may arise from the facultative responses of individuals living in different socioecologies. In other words, individuals in different populations can share the same personality-relevant genetic architecture, but these genes may produce different effects in different environments. A growing body of work within behavioral ecology interprets personality variation as reaction norms that respond over ontogeny to individual condition and socioecological context (Dingemanse, Kazem, Reale, \& Wright, 2010; Sih, Bell, Johnson, \& Ziemba, 2004). A working hypothesis is that coordinated traits might be facultatively calibrated based on cues underlying individual circumstances during development. The bundle of particular items and traits constituting human personality might act like conditional strategies (Buss, 2009; Figueredo et al., 2011; Gangestad \& Simpson, 2000; Lukaszewski \& Roney, 2011; Nettle, 2010; Penke, 2010; Tooby \& Cosmides, 1990). For example, men who are stronger and rated as more attractive are more likely to be extraverted, independent of a genetic polymorphism that also explains some of the covariance (Lukaszewski \& Roney, 2011). Variation in susceptibility to stress, which may underlie differences in neuroticism, has been linked to facultative calibration to stressors early in life (Ellis, Jackson, \& Boyce, 2006). It is an intriguing possibility that pan-human reaction norms shape not only intersocietal differences in average personality scores but also the structure of personality covariation itself, due to sustained socioecological differences across human populations. This hypothesis cannot be rejected in light of recent cross-cultural studies finding universal evidence of the Big Five, given the WEIRD-ness of most of the study populations. Indeed, any model of personality that specifies a fixed set of biologically based trait dimensions would be inconsistent with the results we report here. A comprehensive theory of personality would need to explain how particular conditions might lead to different combinations of calibrated and coordinated items, which then generate multidimensional personality structure, in varied socioecological settings and circumstances. Under a wide range of conditions, the FFM might adequately describe personality variation and necessarily so, but we still do not know why! We therefore speculate about some conditions that differ between WEIRD and small-scale subsistence societies in order to help explain our findings.

What features of Tsimane socioecology cause divergence from the Big Five pattern found in WEIRD populations? Individuals in all human societies face similar goals of learning 
important productive skills, avoiding environmental dangers, cooperating and competing effectively in social encounters, and finding suitable mates. In small-scale societies, however, individuals tend to live in small groups of closely related individuals with greatly reduced choice in social or sexual partners. There are also a limited number of niches by which cultural success may be measured, and proficiency may require abilities that connect items from different traits, thereby leading to low trait reliability and a trait structure other than the FFM. Among the Tsimane, success is defined largely in terms of ability to produce food and provision one's family. Spouses rank each other primarily on these traits and are assortatively matched based on work effort (Gurven et al., 2009). Leadership and allies outside of the extended family accrue to men who are outgoing, trustworthy, and generous among community members (von Rueden et al., 2008). Women's reputations are linked to similar traits and affect their ability to marshal intravillage exchange partnerships (Rucas et al., 2006). Our industriousness and prosociality factors may reflect the different blends of traits conducive to success in the domestic versus the public sphere of Tsimane life. Furthermore, the orthogonality of these factors suggests their effects on fitness are partially independent. Lifetime reproductive success is higher for better producers (Gurven \& von Rueden, 2006) and for higher status individuals (von Rueden, Gurven, \& Kaplan, 2011), and status has a strong effect on reproduction even after controlling for productivity. It is possible that traits may vary more independently in WEIRD societies because of their greater niche diversity and specialization, whether in terms of professional careers or social groups. Success may require a coordinated assortment of fewer items that thereby bundle together in a larger number of factors.

Other considerations might also help explain our findings and would be important to test in other similar societies. Although extended families have relative political autonomy in many small-scale communities, an egalitarian ethic often curtails verbal expression of personal achievement (Boehm, 1999). Thus, the costs and benefits of being extraverted may hinge on one's level of agreeableness, which is suggested by the covariance of Extraversion and Agreeableness items in our prosociality factor. Indeed, Tsimane men whose voiced opinions are most influential in community meetings have more allies and are rated by their peers as more prosocial (von Rueden et al., 2008). McCrae et al. (1998) and Cheung et al. (2001) argued that Extraversion and Agreeableness items have shown different factor structure in East Asian societies because they are more collectivist cultures in which interpersonal affiliation and obedience to authority are more normative. Small-scale societies such as the Tsimane can be characterized as collectivist only in terms of interpersonal affiliation: Their reliance on interhousehold exchange to buffer risk promotes consensual decision making and suppresses the emergence of formal authority (Boehm, 1999; Cashdan, 1980).

Given the day-to-day risks of underproduction relative to subsistence needs, members of small-scale societies tend to be more risk averse (Cancian, 1989; Cashdan, 1990; Kuznar, 2001), and new ideas, values, or experiences are typically met with conservatism. Furthermore, Tsimane and other small-scale populations in the tropics experience high levels of a variety of infectious pathogens (Vasunilashorn et al., 2010), so a cautious and conservative approach to novel people, foods, and practices may reduce the risk of disease (Schaller \& Murray, 2008). In our EFAs, the Openness items of "original" and "ingenious" covary with socially desirable Extraversion and Agreeableness items; perhaps individuals 
who are the most interpersonally imbedded can best manage the risks of being open to new experiences. Items gauging artistic interest also covary with socially desirable traits; playing music and telling stories are the principal forms of artistic expression among the Tsimane and are most overt as "performance" in group settings. It is our impression that Tsimane who are more outgoing tend to be the most eager and creative singers and musicians. On the other hand, the Openness items of "curious" and "likes to reflect" positively covaried, respectively, with the Neuroticism item "moody" and the Agreeableness items "quarrelsome" and "rude." This latter result supports our impression from the Tsimane and other small-scale societies that traits such as introspection and reflection are sometimes viewed as signs of depression or are viewed with suspicion. Openness exhibited low internal reliability and factor congruence in our study, similar to results from other developing countries (e.g., McCrae et al., 2005; Piedmont et al., 2002). Openness does not typically replicate in emic studies with Chinese subjects (e.g., Leung, Cheung, Zhang, Song, \& Xie, 1997), suggesting collectivist norms may limit entrepreneurship and expression in ways that mimic the limited opportunities individuals face in small-scale societies. Resolution of these issues requires more studies of personality in non-WEIRD populations.

\section{Conclusion}

Whether the Big Five personality structure replicates in small-scale societies is crucial to claims of the universality of the FFM or any other fixed factor construct (e.g., HEXACO: Lee \& Ashton, 2004; Big Two: Digman, 1997; General Factor of Personality: Musek, 2007). More important, data from small-scale societies contributes to our understanding of the evolution of human personality differences. The FFM and other structural approaches to personality variation are often criticized for a lack of theoretical justification (e.g., Block, 1995); conceptualizing personality dimensions as evolved motivational systems calibrated based on state-based cues from a particular socioecology has the potential to fill this void. Framing adaptive explanations of this sort in the study of human personality has a precedent in behavioral ecology. Concurrent developments in the biological sciences increasingly show that stable personalities, or "behavioral syndromes," exist in many nonhuman species and can have substantial fitness consequences (for reviews of models and evidence, see Dingemanse \& Wolf, 2010; Sih \& Bell, 2008; Sih et al., 2004; Wolf \& Weissing, 2010). The empirical study of Big Five traits and fitness outcomes in humans is still in its infancy (e.g., Alvergne et al., 2010; Eaves, Martin, Heath, Hewitt, \& Neale, 1990; Nettle, 2005; Roberts, Kuncel, Shiner, Caspi, \& Goldberg, 2007). Human personality research is therefore a ripe area for bridging theoretical models with rich empirical evidence (Nettle \& Penke, 2010). However, empirical evidence in humans must expand beyond the limited scope of WEIRD societies. What we can learn about personality variation in small-scale societies bears on arguments concerning the selection pressures responsible for shaping human personality traits and their structure. It is in small-scale societies that humans have lived for the majority of their existence; the socioecologies of ancestral hunter- gatherers and horticulturalists are the crucible that shaped much of human psychology and behavior. We therefore urge others to conduct similar studies of personality structure in other small-scale, indigenous societies.

We provide the first comprehensive test of the FFM in a small-scale, indigenous societythe Tsimane horticulturalists of Bolivia—and fail to robustly replicate the Big Five. We find 
significant covariance among items across the standard Big Five factors, based on two large samples of self- and spouse-reported personality. Tsimane personality variation may instead be organized along fewer and differently composed dimensions. We find evidence for a Tsimane Big Two organized according to prosociality and industriousness in the context of subsistence labor. Our current results require replication, with emic inventories and with other methods such as those based on behavioral observation or on peer reports by nonTsimane. However, even if other methods were to reveal a Big Five structure, an explanation would still be needed for why verbal reports do not lead to the FFM among Tsimane, even after correction for response biases, but do almost everywhere else in the developed world.

\section{Supplementary Material}

Refer to Web version on PubMed Central for supplementary material.

\section{Acknowledgments}

Funding was provided by the National Institutes of Health and the National Institute on Aging (Grants 2R01AG024119 and 2R56AG024119-06). We are grateful to the Tsimane for their hospitality and collaboration over the years. Gary Lewis provided helpful comments on a draft of this article. We also thank Aaron Lukaszewski for sharing ideas and commenting on a draft of the article.

\section{References}

Allik J, McCrae RR. Toward a geography of personality traits: Patterns of profiles across 36 culture. Journal of Cross-Cultural Psychology. 2004; 35:13-28.

Almagor M, Tellegen A, Waller NG. The Big Seven: A cross-cultural replication and further exploration of the basic dimensions of natural language of trait descriptions. Journal of Personality and Social Psychology. 1995; 69:300-307.

Alvergne A, Jokela M, Lummaa V. Personality and reproductive success in a high-fertility human population. Proceedings of the National Academy of Sciences, USA. 2010; 107:11745-11750.

Ashton MC, Lee K, Goldberg LR, de Vries RE. Higher order factors of personality: Do they exist? Personality and Social Psychology Review. 2009; 13:79-91. [PubMed: 19458345]

Bäckström M, Björklund F, Larsson MR. Five-factor inventories have a major general factor related to social desirability which can be reduced by framing items neutrally. Journal of Research in Personality. 2009; 43:335-344.

Benet-Martínez V, John OP. Los Cinco Grandes across cultures and ethnic groups: Multitraitmultimethod analyses of the Big Five in Spanish and English. Journal of Personality and Social Psychology. 1998; 75:729-750. [PubMed: 9781409]

Benet-Martínez V, Waller NG. Further evidence for the cross-cultural generality of the "Big Seven" model: Imported and indigenous Spanish personality constructs. Journal of Personality. 1997; 65:567-598.

Block J. A contrarian view of the five-factor approach to personality description. Psychological Bulletin. 1995; 117:187-215. [PubMed: 7724687]

Boehm, C. Hierarchy in the forest: The evolution of egalitarian behavior. Cambridge, MA: Harvard University Press; 1999.

Bouchard TJ, Loehlin JC. Genes, evolution, and personality. Behavior Genetics. 2001; 31:243-273. [PubMed: 11699599]

Buss DM. How can evolutionary psychology successfully explain personality and individual differences? Perspectives on Psychological Science. 2009; 4:359-366.

Cancian, F. Economic behavior in peasant communities. In: Plattner, S., editor. Economic anthropology. Stanford, CA: Stanford University Press; 1989. p. 127-170. 
Caprara GV, Barbaranelli C, Borgogni L, Perugini M. The Big Five Questionnaire: A new questionnaire to assess the five-factor model. Personality and Individual Differences. 1993; 15:281-288.

Caprara GV, Perugini M. Personality described by adjectives: The generalizability of the Big Five to the Italian lexical context. European Journal of Personality. 1994; 8:357-369.

Cashdan EA. Egalitarianism among hunters and gatherers. American Anthropologist. 1980; 82:116120.

Cashdan, E. Introduction. In: Cashdan, E., editor. Risk and uncertainty in tribal and peasant societies. Boulder, CO: Westview Press; 1990. p. 1-16.

Ceci SJ. How much does schooling influence general intelligence and its cognitive components? A reassessment of the evidence. Developmental Psychology. 1991; 27:703-722.

Cheung FM, Leung K. Indigenous personality measures: Chinese examples. Journal of Cross-Cultural Psychology. 1998; 29:233-248.

Cheung FM, Leung K, Zhang J-X, Sun H-F, Gan Y-Q, Song W-Z, Xie D. Indigenous Chinese personality constructs: Is the five-factor model complete? Journal of Cross-Cultural Psychology. 2001; 32:407-433.

Chicchon, A. Chimane resource use and market involvement in the Beni Biosphere Reserve. Gainesville, Florida: University of Florida; 1992. Unpublished doctoral dissertation

Church AT, Lonner WJ. The cross-cultural perspective in the study of personality: Rationale and current research. Journal of Cross-Cultural Psychology. 1998; 29:32-62.

Costa, PT., Jr; McCrae, RR. Revised NEO Personality Inventory (NEO PI-R) and NEO Five-Factor Inventory (NEO-FFI): Professional manual. Odessa, FL: Psychological Assessment Resources; 1992.

Costa, PT.; McCrae, RR. C. Halverson, G. Kohnstamm, \& R. Martin. The developing structure of temperament and personality from infancy to adulthood. Hillsdale, NJ: Erlbaum; 1994. 1994. Stability and change in personality from adolescence through adulthood; p. 139-150.

Denissen JJA, Penke L. Motivational individual reaction norms underlying the five-factor model of personality: First steps towards a theory-based conceptual framework. Journal of Research in Personality. 2008; 42:1285-1302.

De Raad B. An expedition in search of a fifth universal factor: Key issues in the lexical approach. European Journal of Personality. 1994; 8:229-250.

DeYoung CG. Higher-order factors of the Big Five in a multi-informant sample. Journal of Personality and Social Psychology. 2006; 91:1138-1151. [PubMed: 17144770]

Di Blas L, Forzi M. An alternative taxonomic study of personality-descriptive adjectives in the Italian language. European Journal of Personality. 1998; 12:75-101.

Digman JM. Personality structure: Emergence of the five-factor model. Annual Review of Psychology. 1990; 41:417-440.

Digman JM. Higher order factors of the Big Five. Journal of Personality and Social Psychology. 1997; 73:1246-1256. [PubMed: 9418278]

Dingemanse NJ, Kazem AJN, Reale D, Wright J. Behavioural reaction norms: Animal personality meets individual plasticity. Trends in Ecology \& Evolution. 2010; 25:81-89. [PubMed: 19748700]

Dingemanse NJ, Wolf M. Recent models for adaptive personality differences: A review. Philosophical Transactions of the Royal Society B: Biological Sciences. 2010; 365:3947-3958.

Eaves LJ, Martin NG, Heath AC, Hewitt JK, Neale MC. Personality and reproductive fitness. Behavior Genetics. 1990; 20:563-568. [PubMed: 2288546]

Ellis BJ, Jackson JJ, Boyce WT. The stress response systems: Universality and adaptive individual differences. Developmental Review. 2006; 26:175-212.

Figueredo, AJ.; Wolf, PSA.; Gladden, PR.; Olderbak, S.; Andrzejczak, DJ.; Jacobs, WJ. Ecological approaches to personality. In: Buss, DM.; Hawley, PH., editors. The evolution of personality and individual differences. Oxford, England: Oxford University Press; 2010. p. 210-239.

Gangestad SW, Simpson JA. The evolution of human mating: Trade-offs and strategic pluralism. Behavioral and Brain Sciences. 2000; 23:573-587. [PubMed: 11301543] 
Goldberg LR. An alternative "description of personality": The Big-Five factor structure. Journal of Personality and Social Psychology. 1990; 59:1216-1229. [PubMed: 2283588]

Guanzon-Lapeña MA, Church AT, Carlota AJ, Katigbak MS. Indigenous personality measures: Philippine examples. Journal of Cross-Cultural Psychology. 1998; 29:249-270.

Gurven M, Kaplan H, Zelada Supa A. Mortality experience of Tsimane Amerindians: Regional variation and temporal trends. American Journal of Human Biology. 2007; 19:376-398. [PubMed: 17421012]

Gurven M, von Rueden C. Hunting, social status, and biological fitness. Biodemography and Social Biology. 2006; 53:81-99.

Gurven M, Winking J. Collective action in action: Pro-social behavior in and out of the laboratory. American Anthropologist. 2008; 110:179-190.

Gurven M, Winking J, Kaplan H, von Rueden C, McAllister L. A bioeconomic approach to marriage and the sexual division of labor. Human Nature. 2009; 20:151-183.

Gurven M, Zanolini A, Schniter E. Culture sometimes matters: Intra-cultural variation in pro-social behavior among Tsimane Amerindians. Journal of Economic Behavior \& Organization. 2008; 67:587-607. [PubMed: 19122839]

Henrich J, Heine SJ, Norenzayan A. The weirdest people in the world? Behavioral and Brain Sciences. 2010; 33:61-83. [PubMed: 20550733]

Hofstee WKB, Ten Berge JMF, Hendriks AAJ. How to score questionnaires. Personality and Individual Differences. 1998; 25:897-909.

Huánca, T. Tsimane' indigeous knowledge, swidden fallow management, and conservation. University of Florida; 1999. Unpublished doctoral dissertation

Jang KL, Livesley W, Angleitner A, Riemann R, Vernon PA. Genetic and environmental influences on the covariance of facets defining the domains of the five-factor model of personality. Personality and Individual Differences. 2002; 33:83-101.

John, OP. The "Big Five" factor taxonomy: Dimensions of personality in the natural language and in questionnaires. In: Pervin, LA., editor. Handbook of personality: Theory and research. New York, NY: Guilford Press; 1990. p. 66-100.

King JE, Figueredo AJ. The five-factor model plus Dominance in chimpanzee personality. Journal of Research in Personality. 1997; 31:257-271.

Kuznar L. Risk sensitivity and value among Andean pastoralists: Measures, models, and empirical tests. Current Anthropology. 2001; 42:432-440.

Lee K, Ashton MC. The HEXACO Personality Inventory: A new measure of the major dimensions of personality. Multivariate Behavioral Research. 2004; 39:329-358.

Leung, K.; Cheung, FM.; Zhang, J-X.; Song, W-Z.; Xie, D. The five-factor model of personality in China. In: Leung, K.; Kashima, Y.; Kim, U.; Yamaguchi, S., editors. Progress in Asian social psychology. Vol. Vol. 1. Singapore: Wiley; 1997. p. 231-244.

Lukaszewski AW, Roney JR. The origins of extraversion: Joint effects of facultative calibration and genetic polymorphism. Personality and Social Psychology Bulletin. 2011; 37:409-421. [PubMed: 21307179]

McCrae, RR. Lonner, WJ.; Dinnel, DL.; Hayes, SA.; Sattler, DN., editors. Cross-cultural research on the five-factor model of personality. 2002. Online readings in psychology and culture (Unit 6 , Chapter 1). Retrieved from http://www.wwu.edu/ culture

McCrae RR, Costa PT Jr. Personality trait structure as a human universal. American Psychologist. 1997; 52:509-516. [PubMed: 9145021]

McCrae RR, Costa PT Jr, Del Pilar GH, Rolland JP, Parker WD. Cross-cultural assessment of the fivefactor model: The revised NEO Personality Inventory. Journal of Cross-Cultural Psychology. 1998; 29:171-188.

McCrae RR, Terracciano A. \& 78 Members of the Personality Profiles of Cultures Project. Universal features of personality traits from the observer's perspective: Data from 50 cultures. Journal of Personality and Social Psychology. 2005; 88:547-561. [PubMed: 15740445]

McCrae RR, Yamagata S, Jang KL, Riemann R, Ando J, Ono Y, ... Spinath FM. Substance and artifact in the higher-order factors of the Big Five. Journal of Personality and Social Psychology. 2008; 95:442-455. [PubMed: 18665712] 
McCrae RR, Zonderman AB, Costa PT Jr, Bond MH, Paunonen SV. Evaluating replicability of factors in the Revised NEO Personality Inventory: Confirmatory factor analysis versus Procrustes rotation. Journal of Personality and Social Psychology. 1996; 70:552-566.

Musek J. A general factor of personality: Evidence for the Big One in the five-factor model. Journal of Research in Personality. 2007; 41:1213-1233.

Narayan S, Krosnick JA. Education moderates some response effects in attitude measurement. Public Opinion Quarterly. 1996; 60:58-88.

Nettle D. An evolutionary approach to the extraversion continuum. Evolution and Human Behavior. $2005 ; 26: 363-373$.

Nettle, D. Evolutionary perspectives on the five-factor model of personality. In: Buss, D.; Hawley, P., editors. The evolution of personality and individual differences. New York, NY: Oxford University Press; 2010. p. 5-28.

Nettle D, Penke L. Personality: Bridging the literatures from psychology and behavioural ecology. Philosophical Transactions of the Royal Society B: Biological Sciences. 2010; 365:4043-4050.

Ortiz FA, Church AT, Vargas-Flores JDJ, Ibáñez-Reyes J, Flores-Galaz M, Iuit-Briceño JI, Escamilla JM. Are indigenous personality dimensions culture-specific? Mexican inventories and the fivefactor model. Journal of Research in Personality. 2007; 41:618-649.

Paunonen SV, Ashton MC. The structured assessment of personality across cultures. Journal of CrossCultural Psychology. 1998; 29:150-170.

Paunonen SV, Ashton MC, Jackson DN. Nonverbal assessment of the Big Five personality factors. European Journal of Personality. 2001; 15:3-18.

Peabody D, De Raad B. The substantive nature of psycholexical personality factors: A comparison across languages. Journal of Personality and Social Psychology. 2002; 83:983-997. [PubMed: 12374448]

Penke, L. Bridging the gap between modern evolutionary psychology and the study of individual differences. In: Buss, DM.; Hawley, PH., editors. The evolution of personality and individual differences. Oxford, England: Oxford University Press; 2010. p. 243-279.

Penke L, Denissen JJA, Miller GF. The evolutionary genetics of personality. European Journal of Personality. 2007; 21:549-587.

Perugini M, Leone L. Construction and validation of a Short Adjectives Checklist to measure Big Five (SACBIF). European Journal of Psychological Assessment. 1996; 12:33-42.

Piedmont, RL.; Bain, E.; McCrae, RR.; Costa, PT, Jr. The applicability of the five-factor model in a sub-Saharan culture: The NEO-PI-R in Shona. In: McCrae, RR.; Allik, J., editors. The five-factor model of personality across cultures. New York, NY: Kluwer Academic; 2002. p. 155-173.

Ramírez-Esparza N, Gosling SD, Benet-Martínez V, Potter JP, Pennebaker JW. Do bilinguals have two personalities? A special case of cultural frame switching. Journal of Research in Personality. 2006; 40:99-120.

Rammstedt B, Goldberg LR, Borg I. The measurement equivalence of Big Five factor markers for persons with different levels of education. Journal of Research in Personality. 2010; 44:53-61. [PubMed: 20401177]

Riemann R, Angleitner A, Strelau J. Genetic and environmental influences on personality: A study of twins reared together using the self- and peer-report NEO FFI scales. Journal of Personality. 1997; 65:449-475.

Roberts BW, Kuncel NR, Shiner R, Caspi A, Goldberg LR. The power of personality: The comparative validity of personality traits, socio-economic status, and cognitive ability for predicting important life outcomes. Perspectives on Psychological Science. 2007; 2:313-345.

Rolland, JP. Cross-cultural generalizability of the five-factor model of personality. In: McCrae, RR.; Allik, J., editors. The five-factor model of personality across cultures. New York, NY: Kluwer Academic; 2002. p. 7-28.

Rucas S, Gurven M, Kaplan H, Winking J, Gangestad S, Crespo M. Female intrasexual competition and reputational effects on attractiveness among the Tsimane of Bolivia. Evolution and Human Behavior. 2006; 27:40-52. 
Schaller M, Murray DR. Pathogens, personality, and culture: Disease prevalence predicts worldwide variability in sociosexuality, extraversion, and openness to experience. Journal of Personality and Social Psychology. 2008; 95:212-221. [PubMed: 18605861]

Schmitt DP, Allik J, McCrae RR, Benet-Martínez V, Alcalay L, Ault L. The geographic distribution of Big Five personality traits: Patterns and profiles of human self description across 56 nations. Journal of Cross-Cultural Psychology. 2007; 38:173-212.

Schniter, E. Why old age? Non-material contributions and patterns of aging among older adult Tsimane. Santa Barbara, California: University of California; 2009. Unpublished doctoral dissertation

Sih A, Bell AM. Insights for behavioral ecology from behavioral syndromes. Advances in the Study of Behavior. 2008; 38:227-281. [PubMed: 24991063]

Sih A, Bell AM, Johnson JC, Ziemba RE. Behavioural syndromes: An integrative overview. Quarterly Review of Biology. 2004; 79:241-277. [PubMed: 15529965]

Soto CJ, John OP, Gosling SD, Potter J. The development psychometrics of the Big Five self-reports: Acquiescence, factor structure, coherence, and differentiation from ages 10 to 20. Journal of Personality and Social Psychology. 2008; 94:718-737. [PubMed: 18361680]

Szirmák Z, De Raad B. Taxonomy and structure of Hungarian personality traits. European Journal of Personality. 1994; 8:95-117.

Tabachnick, BG.; Fidell, LS. Using multivariate statistics. Boston, MA: Allyn \& Bacon; 2001.

Thompson ER. Development and validation of an international English Big-Five mini markers. Personality and Individual Differences. 2008; 45:542-548.

Tooby J, Cosmides L. On the universality of human nature and the uniqueness of the individual: The role of genetics and adaptation. Journal of Personality. 1990; 58:17-67. [PubMed: 2198338]

Triandis, H. Cross-cultural perspectives on personality. In: Hogan, R.; Johnson, J.; Briggs, S., editors. Handbook of personality psychology. San Diego, CA: Academic Press; 1997. p. 439-464.

Vasunilashorn S, Crimmins EM, Kim JK, Winking J, Gurven M, Kaplan H, Finch CE. Blood lipids, infection, and inflammatory markers in the Tsimane of Bolivia. American Journal of Human Biology. 2010; 22:731-740. [PubMed: 20721985]

von Rueden C, Gurven M, Kaplan H. Multiple dimensions of male social status in an Amazonian society. Evolution and Human Behavior. 2008; 29:402-415. [PubMed: 19884954]

von Rueden C, Gurven M, Kaplan H. Why do men seek status? Fitness payoffs to dominance and prestige. Proceedings of the Royal Society B: Biological Sciences. 2011; 278:2223-2232.

Wiggins, JS.; Trapnell, PD. Personality structure: The return of the Big Five. In: Hogan, R.; Johnson, J.; Briggs, S., editors. Handbook of personality psychology. San Diego, CA: Academic Press; 1997. p. 737-765.

Wolf M, Weissing FJ. An explanatory framework for adaptive personality differences. Philosophical Transactions of the Royal Society B: Biological Sciences. 2010; 365:3959-3968.

Yamagata S, Suzuki A, Ando J, Ono Y, Kijima N, Yoshimura K, ... Jang KL. Is the genetic structure of human personality universal? A cross-cultural twin study from North America, Europe, and Asia. Journal of Personality and Social Psychology. 2006; 90:987-998. [PubMed: 16784347] 


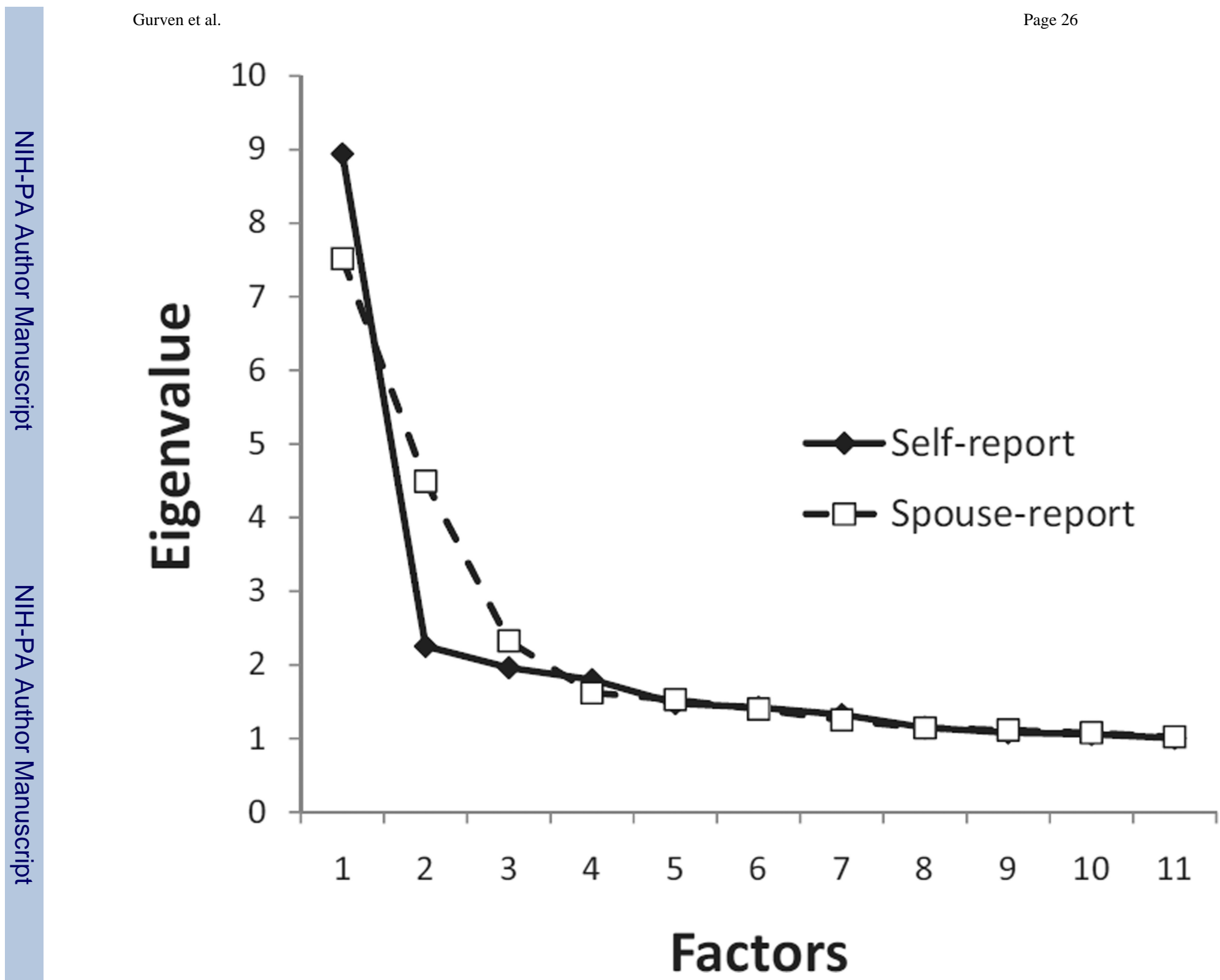

Figure 1.

Scree plots for unrestricted exploratory factor analysis (self-and spouse-report samples). 


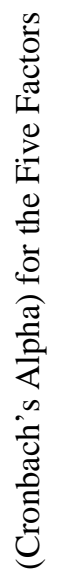

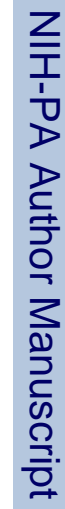

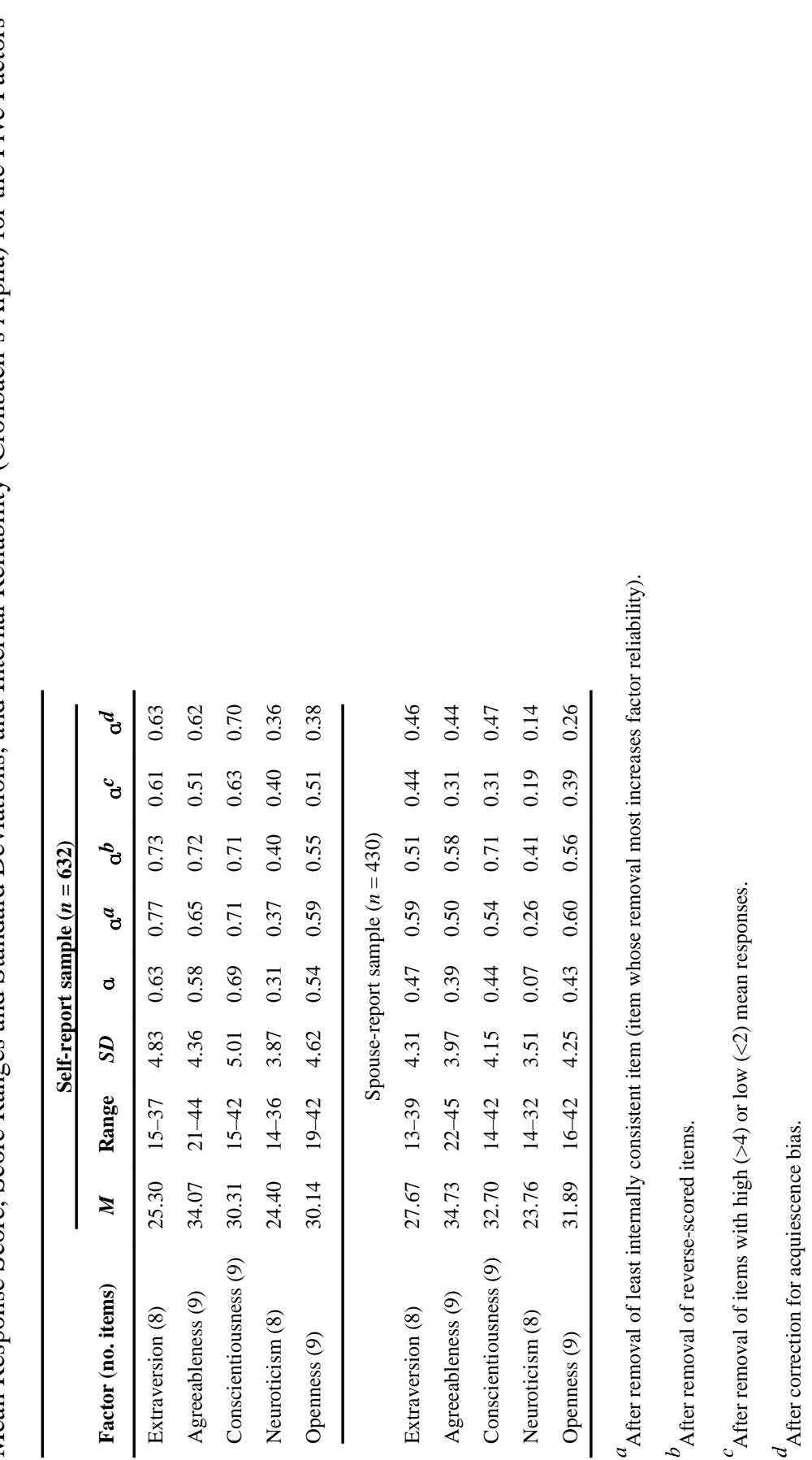

J Pers Soc Psychol. Author manuscript; available in PMC 2014 July 20. 
Table 2

Internal Reliability Based on Cronbach's Alpha for Subgroups of Self-Report Sample

\begin{tabular}{|c|c|c|c|c|}
\hline Factor & $\begin{array}{c}\text { Men } \\
(n=326)\end{array}$ & $\begin{array}{c}\text { Women } \\
(n=306)\end{array}$ & $\begin{array}{c}\text { Older }(>44) \\
(n=310)\end{array}$ & $\begin{array}{c}\text { Young }(\leq 44) \\
(n=321)\end{array}$ \\
\hline Extraversion & 0.61 & 0.53 & 0.62 & 0.65 \\
\hline Agreeableness & 0.57 & 0.59 & 0.64 & 0.53 \\
\hline Conscientiousness & 0.62 & 0.61 & 0.73 & 0.63 \\
\hline Neuroticism & 0.28 & 0.27 & 0.35 & 0.28 \\
\hline \multirow[t]{2}{*}{ Openness } & 0.50 & 0.37 & 0.49 & 0.59 \\
\hline & $\begin{array}{l}\text { Educated } \\
(n=227) \\
\end{array}$ & $\begin{array}{c}\text { Not educated } \\
(n=365) \\
\end{array}$ & $\begin{array}{c}\text { Spanish } \\
(n=315)\end{array}$ & $\begin{array}{c}\text { No Spanish } \\
(n=280)\end{array}$ \\
\hline Extraversion & 0.65 & 0.59 & 0.61 & 0.54 \\
\hline Agreeableness & 0.51 & 0.59 & 0.52 & 0.56 \\
\hline Conscientiousness & 0.60 & 0.69 & 0.58 & 0.67 \\
\hline Neuroticism & 0.31 & 0.30 & 0.30 & 0.30 \\
\hline Openness & 0.59 & 0.46 & 0.51 & 0.44 \\
\hline
\end{tabular}



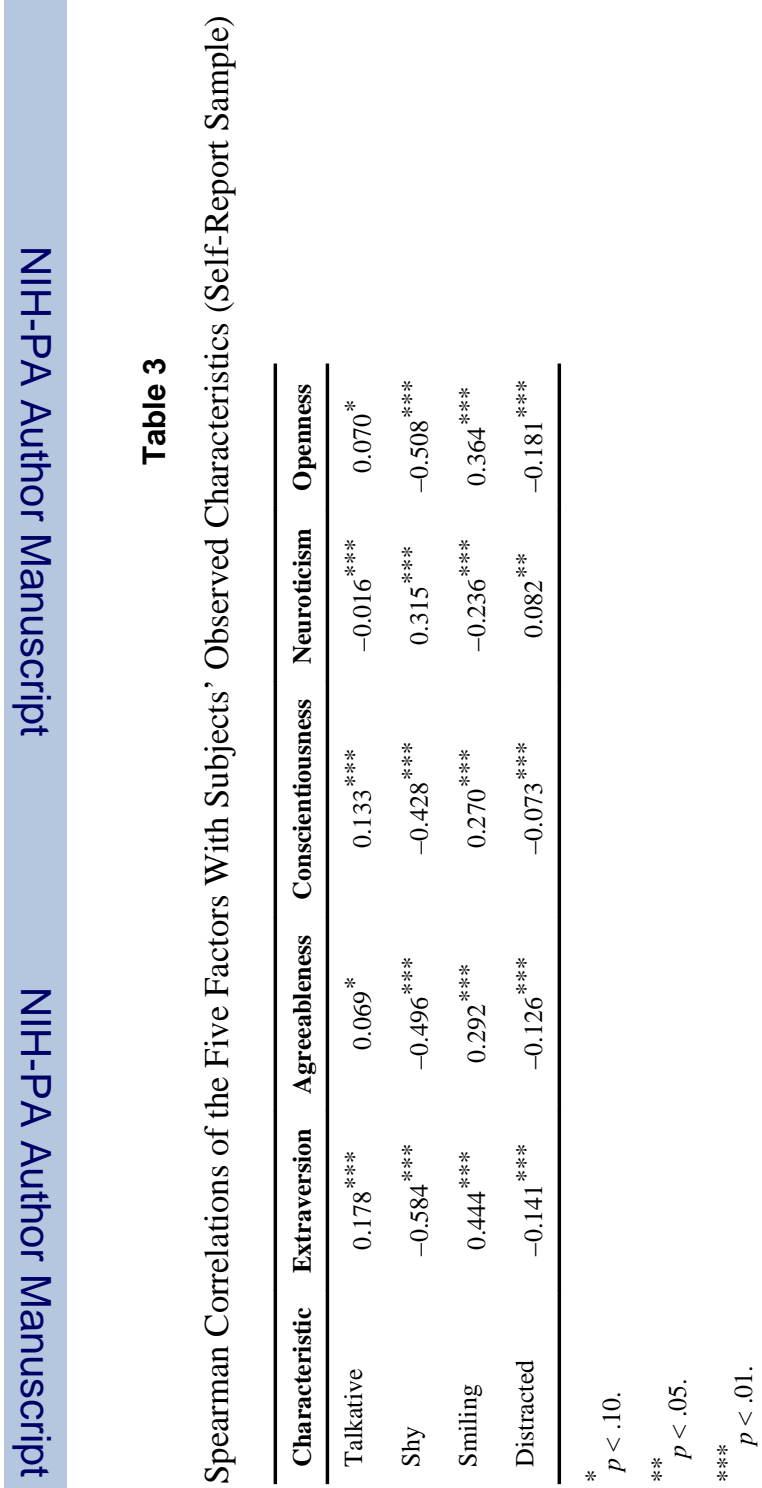

J Pers Soc Psychol. Author manuscript; available in PMC 2014 July 20. 
Table 4

Spearman Correlations Between Factors (Self-Report Sample)

\begin{tabular}{lllll}
\hline Factor & Extraversion & Agreeableness & Conscientiousness & Neuroticism \\
\hline Extraversion & - & - & - & - \\
Agreeableness & 0.534 & - & - & - \\
Conscientiousness & 0.603 & 0.536 & - & - \\
Neuroticism & -0.408 & -0.287 & -0.444 & - \\
Openness & 0.602 & 0.497 & 0.546 & -0.305 \\
\hline
\end{tabular}

Note. All correlations are significant at $p<.01$ level. 
